\title{
Proposal for Prevention of Drowsy Driving-Related Motor Vehicle Accidents in Patients With Obstructive Sleep Apnea
}

\author{
Jun-Sang Sunwoo ${ }^{1}$, Jae Wook Cho ${ }^{2}$, Soo Hwan Yim ${ }^{3}$, Daeyoung Kim ${ }^{4}$, Dae Lim Koo ${ }^{5}$, Hee-Jin Im ${ }^{6}$, \\ Hyeyun Kim ${ }^{7}$, Kyung Min Kim ${ }^{8}$, Kwang IK Yang ${ }^{9}$; On behalf of the Korean Sleep Research Society \\ ${ }^{1}$ Department of Neurosurgery, Seoul National University Hospital, Seoul, \\ ${ }^{2}$ Department of Neurology, Pusan National University Yangsan Hospital, Pusan National University College of Medicine, Yangsan, \\ ${ }^{3}$ Department of Neurology, Gangneung Asan Hospital, Ulsan University College of Medicine, Gangneung, \\ ${ }^{4}$ Department of Neurology, Chungnam National University Hospital, Chungnam National University College of Medicine, Daejeon, \\ ${ }^{5}$ Department of Neurology, Seoul Metropolitan Government Seoul National University Boramae Medical Center, \\ Seoul National University College of Medicine, Seoul, \\ ${ }^{6}$ Department of Neurology, Hallym University Dongtan Sacred Heart Hospital, Hwaseong, \\ ${ }^{7}$ Department of Neurology, International St. Mary's Hospital, Catholic Kwandong University College of Medicine, Incheon, \\ ${ }^{8}$ Department of Neurology, Severance Hospital, Yonsei University College of Medicine, Seoul, \\ ${ }^{9}$ Sleep Disorders Center, Department of Neurology, Soonchunhyang University Cheonan Hospital, Cheonan, Korea
}

\section{폐쇄수면무호흡 환자에서 졸음운전 관련 교통사고 예방을 위한 제안}

선우준상 ${ }^{1}$, 조재욱 ${ }^{2}$, 임수환 ${ }^{3}$, 김대영 ${ }^{4}$, 구대림 ${ }^{5}$, 임희진 ${ }^{6}$, 김혜윤 ${ }^{7}$, 김경민 ${ }^{8}$, 양광익 ${ }^{9}$ 대한수면연구학회

${ }^{1}$ 서울대학교병원 신경외과, ${ }^{2}$ 부산대학교 의과대학 양산부산대병원 신경과학교실, ${ }^{3}$ 울산대학교 의과대학 강릉아산병원 신경과학교실, ${ }^{4}$ 충남대학교 의과대학 충남대학교병원 신경과학교실, ${ }^{5}$ 서울대학교 의과대학 서울특별시보라매병원 신경과학교실,

${ }^{6}$ 한림대학교 의과대학 동탄성심병원 신경과학교실, ${ }^{7}$ 가톨릭관동대학교 의과대학 국제성모병원 신경과학교실,

${ }^{8}$ 연세대학교 의과대학 세브란스병원 신경과학교실, ${ }^{9}$ 순천향대학교 의과대학 천안병원 수면장애센터 신경과학교실

Received November 23, 2021 Accepted November 26, 2021

Address for correspondence Kwang Ik Yang, MD, PhD Sleep Disorders Center, Department of Neurology, Soonchunhyang University Cheonan Hospital,

31 Soonchunhyang 6-gil,

Dongnam-gu,

Cheonan 31151, Korea

Tel: $+82-41-570-2290$

Fax: +82-41-592-3810

E-mail: neurofan@schmc.ac.kr
Obstructive sleep apnea (OSA) is known to be associated with various health concerns, including sleepiness, fatigue, cognitive dysfunction, diminished quality of life, hypertension, cardiovascular diseases, and stroke. OSA-induced sleepiness at the wheel reduces vigilance and driving performance, which significantly increase the risk of motor vehicle accidents. Sleepiness-induced motor vehicle accidents are characterized by high morbidity and mortality. OSA is a well-established significant risk factor for drowsy driving-related motor vehicle accidents, which can be prevented through appropriate treatment. However, currently no clinical guidelines or regulations are available for evaluation or management of the risk of motor vehicle accidents in patients with OSA in Korea. In this review, we discuss the risk of motor vehicle accidents in patients with OSA, the effects of positive airway pressure therapy as a preventive measure to reduce this risk, and the published recommendations for OSA in other countries with regard to fitness to drive. We propose recommendations for screening, evaluation, and treatment of OSA with regard to the risk of motor vehicle accidents, which would serve as useful practical guidelines for sleep specialists in clinical practice. Further research is warranted to establish optimal strategies for effective improvements in OSA-related traffic safety.

J Sleep Med 2021;18(3):127-136

Keywords: Obstructive sleep apnea; Traffic accidents; Continuous positive airway pressure; Sleepiness; Polysomnography.

This is an Open Access article distributed under the terms of the Creative Commons Attribution Non-Commercial License (https://creativecommons.org/licenses/bync/4.0) which permits unrestricted non-commercial use, distribution, and reproduction in any medium, provided the original work is properly cited. 


\section{서 론}

폐쇄수면무호흡(obstructive sleep apnea)은 가장 흔한 수 면관련호흡장애로 수면 중 반복적으로 발생하는 부분적 또 는 완전한 상기도 허탈을 특징으로 한다. ${ }^{1}$ 우리나라 성인 남 성의 $4.5 \%$ 와 여성의 $3.2 \%$ 가 폐쇄수면무호흡을 가지고 있다. ${ }^{2}$ 폐쇄수면무호흡이 건강에 미치는 영향은 광범위하여 과다주 간졸림, 피로, 인지기능과 삶의 질 저하를 유발하고, 고혈압, 관상동맥질환, 울혈성 심부전, 부정맥 및 뇌졸중의 발생 위험 을 증가시킨다. 또한, 폐쇄수면무호흡은 졸음운전(drowsy driving)을 유발하고 각성 및 수행능력을 감소시켜 교통사고 의 위험을 유의하게 증가시킨다. ${ }^{4}$

졸음운전은 교통사고와 그로 인한 부상 및 사망의 위험 요 소로 잘 알려져 있으며, 메타분석 결과 졸음운전은 교통사고 의 위험을 약 2.5 배 증가시킨다. ${ }^{5}$ 특히 졸음운전과 관련된 교 통사고는 중증도와 사망률이 높은 특징이 있으며, 이는 졸음 운전에 의한 교통사고에서는 운전자의 반응이 지연되고 충 돌 시 차량의 주행속도가 빠르기 때문이다. 미국에서 2009년 부터 2013년까지 발생한 교통사고를 분석한 결과 입원이 필 요한 교통사고의 $13 \%$ 와 사망을 유발한 교통사고의 $21 \%$ 가 졸음운전과 관련이 있었다. ${ }^{6}$ 또한, 미국에서 연간 약 800,000 명의 운전자가 폐쇄수면무호흡과 관련된 교통사고를 겪으며 1,400 명이 사망하고 연간 159 억 달러의 비용이 발생하는데, 폐쇄수면무호흡 운전자를 모두 치료한다고 가정하면 연간 111억 달러의 비용과 980명의 생명을 구할 것으로 추산된다. 우리나라에서도 졸음운전으로 인한 교통사고의 위험과 심 각성에 대한 사회적 인식이 높아지면서 졸음쉼터 설치, 사업 용 운전자의 근로여건 개선 및 안전교육 강화, 차량 내 안전 장비 설치 등의 방안이 제시되었다. ${ }^{8}$ 하지만 폐쇄수면무호흡 이 졸음운전과 관련된 교통사고의 위험인자이고 적절한 치 료를 통해 그 위험을 예방할 수 있다는 사실이 잘 알려져 있 음에도 불구하고, ${ }^{910}$ 아직까지 국내에서 운전자에 대한 폐쇄 수면무호흡의 선별, 진단 및 치료에 대한 임상지침이나 법령 또는 행정규칙은 전무한 실정이다. 따라서, 본 종설에서는 지난 호 종설에 이어 1) 폐쇄수면무호흡이 운전자의 교통사 고 위험에 미치는 영향, 2) 지속기도양압이 교통사고 위험을 감소시키는 효과, 3) 다른 나라의 폐쇄수면무호흡 관련 운전 지침을 고찰한다. ${ }^{11}$ 마지막으로, 우리나라에서 폐쇄수면호흡 을 동반한 운전자에서 졸음운전과 관련된 교통사고를 예방 하기 위한 방안을 제안한다.

\section{본 론}

\section{폐쇄수면무호흡과 교통사고 위험}

미국 위스콘신수면코호트에 참여한 성인 913명을 대상으 로 폐쇄수면무호흡 유무와 5년간의 교통사고 발생률을 조사 한 결과, 폐쇄수면무호흡이 있는 남성은 교통사고 발생이 3배 증가했다. 특히, 중등도 이상의 폐쇄수면무호흡이 있는 경우 는 5년 동안 한번 이상의 교통사고를 경험할 위험이 남녀 모 두에서 7.3 배 증가했다. ${ }^{12}$ 또한, 교통사고를 경험한 운전자와 그렇지 않은 운전자를 비교한 환자-대조군 연구도 비슷한 결과를 보였다. 교통사고를 경험한 운전자에서 폐쇄수면무 호흡의 빈도는 $28.4 \%$ 로 대조군의 $4.6 \%$ 에 비해 유의하게 높 았다. 중등도 이상의 폐쇄수면무호흡의 비율은 교통사고를 경험한 운전자에서 8.1배 증가하여 둘 사이의 유의한 연관성 을 뒷받침했다. ${ }^{13}$ 특히, 음주를 한 운전자를 대상으로 분석하 면 교차비가 11.2로 증가하여 음주가 폐쇄수면무호흡과 교통 사고의 연관성을 증가시키는 요인으로 작용함을 시사한다. 또한, 사고의 중증도와 관련하여 운전자의 폐쇄수면무호흡 은 신체 손상을 수반하는 교통사고의 위험을 더욱 증가시킨 다. ${ }^{14}$ 국내에서 일반 성인 1,675 명을 대상으로 시행한 설문지 연구에서 $23.6 \%$ 가 졸음운전을 경험했으며, 그 중 $33.1 \%$ 는 졸음운전의 빈도를 한 달에 한번 이상으로 보고했다. 졸음운 전을 경험한 운전자에서 베를린 설문지로 평가한 폐쇄수면 무호흡의 고위험군 빈도는 $11.6 \%$ 로 대조군의 $7.5 \%$ 에 비해 유의하게 높았고, 과다주간졸림의 빈도 역시 $17.4 \%$ 로 대조 군의 $8.8 \%$ 에 비해 유의하게 높았다. 다변량 분석에서 습관적 인 코골이가 있는 운전자는 졸음운전의 위험이 1.53 배로 유 의하게 증가했으며, 이는 폐쇄수면무호흡과 졸음운전의 연 관성을 간접적으로 뒷받침한다. ${ }^{15}$

사업용 운전자(commercial motor vehicle drivers)의 교통 사고는 대형사고와 그로 인한 치명적인 부상 및 사망의 위험 이 높기 때문에 교통안전의 중요성이 매우 크다. 사업용 운전 자는 남성, 비만, 음주, 운동 부족, 건강에 해로운 식생활 등 폐쇄수면무호흡의 위험인자를 동반하는 경우가 흔하다. ${ }^{16,17}$ 또한, 폐쇄수면무호흡이 사고의 위험을 증가시키는 효과는 다른 종류의 직업군보다 특히 사업용 운전자 직업군에서 크 게 작용한다. ${ }^{4}$ 호주의 사업용 운전자 161 명을 대상으로 야간 수면다원검사를 시행한 결과 호흡장애지수(respiratory disturbance index) 5 회/시간 이상의 폐쇄수면무호흡의 유병률 은 59.6\%, 과다주간졸림이 동반된 폐쇄수면무호흡증후군 (obstructive sleep apnea syndrome)의 유병률은 $15.8 \%$ 로 나 타났고, ${ }^{18}$ 이는 일반 성인남성에서 유병률(각각 $24 \%$ 와 $4 \%$ )에 비해서 훨씬 높다. ${ }^{19}$ 대형차량운전자 200 명을 분석한 연구에 
서는 중등도 이상의 폐쇄수면무호흡이 $42.2 \%$ 에서 발견되었 고 ${ }^{20}$ 이 역시 일반 성인남성에서 유병률(7\%-14\%)에 비해 훨 씬 높다. ${ }^{21}$ 이 연구에서 폐쇄수면무호흡이 동반된 대형차량 운전자는 교통사고의 위험이 3.4배 증가했고, 그 외에도 젊은 나이, 우울증, 피로 관리 훈련 부족이 교통사고 위험과 유의 하게 연관됐다. 트럭운전자 949 명에서 베를린 설문지를 기반 으로 진단한 폐쇄수면무호흡의 빈도는 $25.8 \%$ 였으며, 폐쇄수 면무호흡이 동반된 트럭 운전자는 교통사고 및 아차사고의 위험이 각각 2.32배와 2.39배 유의하게 증가하는 결과를 보 였다. 22 그 밖에 관련된 인자들로 수면부족과 과다주간졸림 은 교통사고의 위험을 증가시키는 반면, 낮잠이나 운전 중 휴식은 사고 위험을 유의하게 감소시켰다. 국내 사업용 운전 자 110 명에서 베를린 설문지를 조사한 연구에서는 폐쇄수면 무호흡 고위험군의 빈도가 $35.5 \%$ 로 대조군의 $12.2 \%$ 보다 유 의하게 높았고, 나이, 체질량지수 및 음주 등의 교란변수를 보정한 이후에도 사업용 운전자는 폐쇄수면무호흡의 고위 험군이 될 가능성이 3.7배 증가하는 독립적인 연관성을 보였 다. ${ }^{17}$ 또한, 가정용수면무호흡검사 Watch-PAT 200을 이용하 여 국내 사업용 운전자를 평가한 연구에서 폐쇄수면무호흡 의 전체 유병률은 $91 \%$ 였고 중등도 이상의 폐쇄수면무호흡의 유병률은 $23.6 \%$ 로 관찰됐고 ${ }^{23}$ 이는 사업용 운전자에서 폐쇄 수면무호흡의 위험이 증가했던 외국 연구들과 일치하는 결 과이다. 중등도 이상의 폐쇄수면무호흡이 동반된 사업용 운 전자는 교통사고와 아차사고(near-miss accident)의 빈도가 각각 $16.7 \%$ 와 $47.6 \%$ 로 대조군의 $7.7 \%$ 와 $34.8 \%$ 에 비해서 높 은 경향을 보였으나 통계적으로 유의하지 않았다. 폐쇄수면 무호흡과 교통사고 위험에 대한 대표적인 연구 결과들을 Table 1에 정리했다.

사업용 및 비사업용 운전자를 모두 포함하여 과거 10 개 연 구들을 메타 분석한 결과를 보면 폐쇄수면무호흡이 있는 운 전자에서 교통사고 위험은 정상 대조군에 비해 2.43배( $95 \%$ 신뢰구간, 1.21-4.89) 증가했다. ${ }^{9}$ 특히, 폐쇄수면무호흡이 동 반된 운전자에서 비만, 야간 저산소혈증은 교통사고 발생의 위험을 증가시키는 경향을 보였다. 다만, 무호흡-저호흡지수 (apnea-hypopnea index)는 교통사고를 경험한 운전자들에 서 더 높은 경향이 있으나 통계적으로 유의하지는 않았다(표 준화된 평균차, $0.27 ; 95 \%$ 신뢰구간, -0.006 - 0.54). 또한 여 러 연구에서 상반된 결과를 보였기 때문에, 무호흡-저호흡지 수로 측정한 폐쇄수면무호흡의 중증도가 교통사고 위험과 관련이 있는지는 아직 결론을 내릴 수 없다. 또한, 폐쇄수면 무호흡이 동반된 운전자에서 과다주간졸림이 교통사고 위험 에 미치는 영향도 연구마다 차이가 있다. 일부 연구에서 엡워 스졸림척도(Epworth sleepiness scale)가 높은 운전자에서 교
통사고 위험이 증가했으나, ${ }^{18,24,25}$ 다른 연구에서는 유의한 차 이가 없었다. ${ }^{12,13}$ 이는 설문지를 통해 평가한 주관적인 졸림의 정도가 대상자의 운전능력에 미치는 영향을 평가하기에는 불 충분하기 때문일 수 있다. 다중수면잠복기검사(multiple sleep latency test)로 객관적인 졸림의 정도를 평가한 연구에서도 교통사고 경험 유무와 평균수면잠복기는 유의한 차이가 없 었다. ${ }^{12}$ 따라서, 폐쇄수면무호흡 환자에서 과다주간졸림이 교 통사고의 독립적인 위험인자로 작용하는지 여부는 아직 불 분명하다.

\section{교통사고 예방에 대한 지속기도양압의 효과}

폐쇄수면무호흡의 치료에는 행동요법, 구강 내 장치, 수술 등 다양한 적용 가능한방법이 있으나 현재 성인 폐쇄수면무 호흡의 최우선치료(treatment of choice)는 지속기도양압 (continuous positive airway pressure)이다. 미국수면학회 (American Academy of Sleep Medicine) 지침에 따르면 지 속기도양압의 적응증은 중등도와 중증(standard) 및 경증 (option)의 폐쇄수면무호흡이다. ${ }^{26}$ 또한 경증 이상의 폐쇄수면 무호흡에서 과다주간졸림 호전(standard) 또는 삶의 질 개선 이나 동반된 고혈압의 조절(option)도 지속기도양압의 적응 증에 포함된다. ${ }^{26}$ 다양한 무작위대조군 연구를 통해 지속기도 양압의 사용은 과다주간졸림의 호전, 고혈압과 인슐린 민감 도 개선, 심혈관질환 감소, 인지기능 및 삶의 질 호전, 뇌경색 후 신경학적 회복 등 폐쇄수면무호흡의 동반질환 또는 합병 증의 위험을 낮추는 효과를 보였다. ${ }^{27}$ 뿐만 아니라, 지속기도 양압은 교통사고의 위험을 감소시키는 효과도 있다. 210 명의 폐쇄수면무호흡 환자의 교통사고 발생률은 대조군에 비해서 약 3배 높았으나 지속기도양압 치료 후 3년 동안의 교통사고 발생률은 대조군과 동일한 수준으로 유의하게 감소했다. ${ }^{28}$ 모 의 운전 장치를 이용한 연구에서도 지속기도양압 치료군은 주관적 및 객관적 졸림 지표, 조향성능과 반응시간이 대조군 에 비해 유의하게 호전되는 효과를 보였고, ${ }^{29}$ 이는 지속기도 양압이 교통사고 발생 위험을 감소시키는 효과를 뒷받침한 다. 엡워스졸림척도나 각성유지검사(maintenance of wakefulness test)로 평가한 졸림의 호전 정도는 운전능력의 호전 과 연관성이 없었는데, 이는 폐쇄수면무호흡 환자의 운전능 력 저하 또는 교통사고 위험이 단순히 졸림에 의한 것이 아 니라 여러 인자의 복합적인 관계에 의해 발생함을 시사한다.

스웨덴에서 교통사고 레지스트리를 이용한 후향적 코호 트 연구에서 폐쇄수면무호흡이 동반된 운전자는 대조군에 비해 교통사고 위험이 2.5 배 높았는데, 지속기도양압치료를 하루 4시간 이상 사용 후 교통사고 발생률은 $70 \%$ 감소했고, 지속기도양압을 사용하지 않거나 순응도가 낮은 환자군은 
Table 1. Summary of studies on OSA and MVA risk

\begin{tabular}{|c|c|c|c|}
\hline Authors & Study population & OSA prevalence & Findings \\
\hline Young et al. ${ }^{12}$ & $\begin{array}{l}\text { General adult population from the } \\
\text { Wisconsin Sleep Cohort ( } \mathrm{n}=913) \text {; } \\
\text { age, } 45.1 \pm 7.8 \text { years; men, } 59 \%\end{array}$ & $\begin{array}{l}\mathrm{AHI} \geq 5: 25 \% \\
\mathrm{AHI} \geq 15: 10 \%\end{array}$ & $\begin{array}{l}\text { OR }(95 \% \mathrm{CI}) \text { for any MVA in } 5 \text { years } \\
\quad-\mathrm{AHI} 5 \text { to }<15 \text { (men): } 4.2(1.6-11.3) \\
\text {-AHI } \geq 15 \text { (men): } 3.4(1.4-8.0) \\
\text { OR ( } 95 \% \mathrm{CI}) \text { for multiple MVA in } 5 \text { years } \\
\text {-AHI } \geq 15 \text { (overall): } 7.3 \text { (1.8- above } 25.0)\end{array}$ \\
\hline Terán-Santos et al. ${ }^{13}$ & $\begin{array}{l}\text { Noncommercial drivers who } \\
\text { experienced MVA ( } n=102) \text { and } \\
\text { controls ( } n=152) \text { in Spain; } \\
\text { age, } 44 \pm 10 \text { years; men, } 23 \%\end{array}$ & $\begin{array}{l}\mathrm{AHI} \geq 5: 14.2 \% \\
\mathrm{AHI} \geq 15: 8.7 \%\end{array}$ & $\begin{array}{l}\text { OR }(95 \% \text { CI }) \text { for MVA } \\
\qquad-A H I \geq 5: 11.1(4.0-30.5) \\
- \text { AHI } \geq 15: 8.1(2.4-26.5)\end{array}$ \\
\hline Mulgrew et al. ${ }^{14}$ & $\begin{array}{l}\text { Patients with suspected OSA } \\
(\mathrm{n}=783) \text { and controls }(\mathrm{n}=783) \\
\text { in Canada; age, } 49.9 \pm 11.6 \text { years; } \\
\text { men, } 71.1 \%\end{array}$ & $\begin{array}{l}\text { AHI } 5 \text { to }<15: 30.0 \% \\
\text { AHI } 15 \text { to }<30: 26.3 \% \\
\text { AHI } \geq 30: 25.8 \%\end{array}$ & $\begin{array}{l}\text { RR }(95 \% \text { CI }) \text { for total MVA in } 3 \text { years } \\
\quad \text {-AHI } 5 \text { to }<15: 2.6(1.7-3.9) \\
\text {-AHI } 15 \text { to }<30: 1.9(1.2-2.8) \\
\text {-AHI } \geq 30: 2.0(1.4-3.0) \\
\text { RR }(95 \% \text { CI }) \text { for MVA with personal } \\
\text { injury in } 3 \text { years } \\
\text {-AHI } 5 \text { to }<15: 4.8(1.8-12.4) \\
\text {-AHI } 15 \text { to }<30: 3.0(1.3-7.0) \\
\text {-AHI } \geq 30: 4.3(1.8-8.9)\end{array}$ \\
\hline Howard et al. ${ }^{18}$ & $\begin{array}{l}\text { Commercial motor vehicle drivers } \\
(n=161) \text { in Australia; age, } \\
47.8 \pm 9.3 \text { years; men, } 99.4 \%\end{array}$ & $\begin{array}{l}\text { RDI } 5 \text { to }<15: 34.8 \% \\
\text { RDI } 15 \text { to }<30: 14.3 \% \\
\text { RDI } \geq 30: 10.6 \%\end{array}$ & $\begin{array}{l}\text { OR }(95 \% \text { CI }) \text { for MVA } \\
\text {-RDI increase in } 1 \text { SD: } 0.82(0.15-3.57) \\
\text {-Epworth sleepiness scale score: } 1.18 \\
\quad(1.09-1.29)\end{array}$ \\
\hline Meuleners et al. ${ }^{20}$ & $\begin{array}{l}\text { Commercial motor vehicle drivers } \\
\text { who were involved in MVA } \\
(\mathrm{n}=100) \text { and not involved in } \\
\text { MVA (control, } \mathrm{n}=100) \text { in } \\
\text { Australia; age, } 44.8 \pm 11.8 \text { years; } \\
\text { men, } 99.0 \%\end{array}$ & $\begin{array}{l}\text { AHI > 17: } 42 \% \text { (measured by } \\
\text { FlowWizard device) }\end{array}$ & $\begin{array}{l}\text { OR (95\% CI) for MVA } \\
\quad-\text { AHI > 17: } 3.42(1.34-8.72)\end{array}$ \\
\hline Kim et al. ${ }^{23}$ & $\begin{array}{l}\text { Commercial motor vehicle drivers } \\
(\mathrm{n}=89) \text { in Korea; age, } 41.5 \pm 10.4 \\
\text { years; men, } 100 \%\end{array}$ & $\begin{array}{l}\text { RDI } 5 \text { to }<15: 67.4 \% \\
\text { RDI } 15 \text { to }<30: 16.9 \% \\
\text { RDI } \geq 30: 6.7 \% \text { (measured by } \\
\text { Watch-PAT } 200 \text { ) }\end{array}$ & $\begin{array}{l}\text { OR }(95 \% \mathrm{CI}) \text { for near-miss MVA } \\
- \text { RDI } \geq 15: 1.37(0.42-4.49) \\
\text { OR (95\% CI) for drowsy driving } \\
\quad-\text { RDI } \geq 15: 1.32(0.39-4.51)\end{array}$ \\
\hline
\end{tabular}

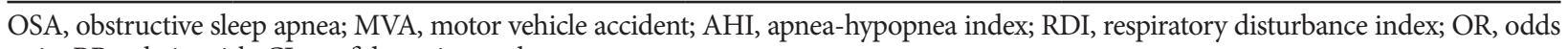
ratio; $\mathrm{RR}$, relative risk; $\mathrm{CI}$, confidence interval

교통사고 발생률이 오히려 $54 \%$ 증가하는 결과를 보였다. ${ }^{25}$ 65세 이상의 노인 폐쇄수면무호흡 환자에서 지속기도양압의 효과를 평가한 다기관 무작위대조군 연구에서 과다주간졸림 은 유의하게 호전됐으나 교통사고 및 모든 종류의 사고 발생 률은 대조군과 차이가 없었다. ${ }^{30}$ 하지만 1 년째 지속기도양압 을 하루 4 시간 이상 사용한 대상자는 $35 \%$ 에 불과했고 평균 지속기도양압 사용시간은 1 시간 26분으로, 지속기도양압의 교통사고 예방 효과를 보였던 과거 연구들에 비해 현저히 낮 은 순응도를 보였다. 따라서, 낮은 치료 순응도 때문에 지속 기도양압의 효과가 교통사고 발생을 감소시키기에 불충분 했을 것으로 해석할 수 있다. 지속기도양압의 순응도와 관련 하여 폐쇄수면무호흡이 동반된 사업용 운전자를 조사한 연
구에서 최소 사용 기준을 만족한 운전자는 1주째 $68.0 \%$ 에서 1 년째 $39.6 \%$ 까지 감소했으며, 일반적인 폐쇄수면무호흡 환 자와 마찬가지로 초기 순응도가 장기적인 지속기도양압 사 용의 유의한 예측 인자였다. ${ }^{31}$ 따라서, 지속기도양압 처방 후 순응도에 모니터링은 필수적이며, 초기에 치료순응도가 낮 은 운전자들을 선별하고 성공적인 적응을 위한 중재가 도움 이 될 수 있다. 또한 과다주간졸림의 개선을 포함한 지속기도 양압의 효과는 사용시간에 용량-의존적이기 때문에, ${ }^{32}$ 교통 사고 예방 효과를 최대화하기 위해서 지속기도양압을 최소 사용 기준(예를 들어, 하루 4시간 이상 사용한 날이 $70 \%$ 이 상)을 넘어서 가급적 많이 사용할 것을 권장한다.

지속기도양압의 효과에 대한 메타 분석 결과 교통사고 발 
생 위험은 $55 \%$ 감소하고, 아차사고의 위험 역시 $77 \%$ 감소하 는 유의한 결과를 보였다. ${ }^{10}$ 특히, 교통사고와 아차사고 1 건을 예방하기 위한 최소치료환자수(numbers needed to treat)가 각각 5 명과 2 명인 점을 고려하면, 지속기도양압이 폐쇄수면 무호흡 운전자에서 매우 비용 효율적인 치료임을 시사한다. 따라서 교통사고와 그로 인한 사회경제적 손실을 줄이기 위 해서 진단되지 않은 폐쇄수면무호흡을 효과적으로 선별하고 교통사고의 발생 위험이 높은 폐쇄수면무호흡 환자들이 적 절한 치료를 받도록 하는 의학적 및 정책적 체계가 필요하다.

\section{다른 나라의 권고사항}

운전과 관련하여 폐쇄수면무호흡의 선별, 진단, 치료에 대 한 대표적인 지침으로 2012년도 미국에서 자동차운송업체 안전자문위원회(Motor Carrier Safety Advisory Committee, $\mathrm{MCSAC}$ )와 의료심사위원회(Medical Review Board, MRB) 가 공동으로 제안한 권고사항이 있다(Table 2). ${ }^{33}$ 이는 사업용 운전자의 운전적합도를 결정하기 위해 개발된 지침으로, 무 호흡-저호흡지수>20회/시간의 중등도 이상의 폐쇄수면무 호흡은 치료가 권장된다. 폐쇄수면무호흡이 있더라도 무호 흡-저호흡지수 $\leq 20$ 회/시간이면서 과다주간졸림이 없거나, 폐쇄수면무호흡이 효과적으로 치료되고 있는 경우는 운전
적합도를 인증 받을 수 있다. 무호흡-저호흡지수 5-20회/시 간의 운전자는 졸음운전이나 그로 인한 교통사고의 병력이 있는 경우에 치료를 받도록 격려한다. 폐쇄수면무호흡이 진 단된 운전자는 치료 순응도를 입증하면 매년 재인증을 받을 수 있고, 기도양압(positive airway pressure)치료의 최소 허 용 순응도는 사용 기간의 $70 \%$ 이상에서 최소 하루 4 시간 사 용이다. 그러나, 운전자는 기도양압을 하루 7시간 이상 사용 했을 때 최적의 치료 효과를 얻을 수 있음을 인지해야 하고, 따라서 최소 사용 기준보다 더 많이 기도양압을 사용할 것을 권장한다. 만일, 폐쇄수면무호흡이 진단된 운전자가 순응도 기준을 만족하지 못하면 즉시 자격이 상실되거나 인증이 거 부된다. 또한, 운전 중 과도한 졸림이 있거나 졸음운전으로 인한 교통사고를 경험한 경우에도 인증이 거부된다.

진단되지 않은 폐쇄수면무호흡을 선별하기 위해 체질량지 수가 $35 \mathrm{~kg} / \mathrm{m}^{2}$ 이상인 운전자는 수면다원검사를 받아야 한 다. 폐쇄수면무호흡 관련 증상으로 코골이, 목격된 무호흡, 과다주간졸림이 있고, 폐쇄수면무호흡의 고위험 인자로 작 은턱증(micrognathia)이나 아래턱후퇴증(retrognathia), Mallampati 분류 3-4점의 작은 기도, 목 둘레 > 17 인치(남성) 또 는 > 15.5 인치(여성), 치료하지 않은 고혈압, 당뇨병, 갑상선 기능저하증의 병력이 있다. 그러나 단일 위험인자만으로는

Table 2. Summary of MCSAC-MRB recommendations for commercial motor vehicle drivers ${ }^{33}$

\begin{tabular}{ll}
\hline \multicolumn{1}{c}{ Topic } & \multicolumn{1}{c}{ Recommendations } \\
\hline General recommendations & AHI $>20$ events/h: treatment recommended \\
& AHI 5-20 events/h: treatment encouraged in high-risk drivers* \\
& May be certified if 1 ) AHI $\leq 20$ events/hr and no EDS, or 2) OSA is being effectively treated \\
Minimally acceptable compliance of PAP & At least 4 hours per day of use on $70 \%$ of days \\
Disqualification or certification denial & Experiencing excessive sleepiness while driving or crashes associated with falling asleep, \\
& or being non-compliant with treatment \\
OSA screening & Body mass index $>35$ kg/m ${ }^{2}$ \\
& Subjective symptoms: loud snoring, witnessed apneas, or EDS \\
& Risk factors of OSA: micrognathia or retrognathia, small airway of Mallampati Scale 3 or 4, \\
& neck circumference $>17$ inches (male) or 15.5 inches (female), history of untreated \\
& hypertension, type 2 diabetes, or hypothyroidism \\
In-lab PSG is more comprehensive & FDA-approved HSAT which ensures chain of custody is also acceptable \\
Polysomnography (PSG) & Consider in-lab PSG if another sleep disorder in addition to OSA is suspected, or the level \\
& of apnea is underestimated by HSAT \\
PAP is the preferred OSA therapy & PAP pressure should be established by either a titration study or an autotitration system \\
Conditionally certified if 1) successfully treated for 1 week, 2) meet the minimal & compliance, and 3) not report EDS \\
\hline
\end{tabular}
*having a history of sleepiness- or fatigue-related motor vehicle crashes, single vehicle crashes, or reporting sleepiness while operating a motor vehicle. AHI, apnea-hypopnea index; EDS, excessive daytime sleepiness; OSA, obstructive sleep apnea; PAP, positive airway pressure; HSAT, home sleep apnea testing, FDA, Food and Drug Administration; MCSAC, Motor Carrier Safety Advisory Committee; MRB, Medical Review Board 
위험을 유추할 수 없으며, 여러 위험인자가 복합된 경우 검 사가 필요하다. 폐쇄수면무호흡의 진단방법으로 검사실(inlab) 또는 제1형(level 1) 수면다원검사가 보다 포괄적인 검 사로 추천되지만, 가정용(at-home) 수면다원검사 또는 관리 연속성이 보장되고 식품의약품안전청에서 승인된 이동형 수면검사장치도 가능하다. 다만, 폐쇄수면무호흡 외 다른 동 반된 수면질환이 의심되는 환자, 또는 가정용 수면다원검사 결과가 과소평가됐다고 의심되는 경우에는 제 1 형 수면다원 검사를 고려해야 한다. 기도양압은 폐쇄수면무호흡의 최우 선 치료이며 적정 압력은 수면다원검사를 통한 압력적정검 사(titration study) 또는 자동적정(autotitration)시스템 중 한 가지 방법으로 결정한다. 만일, 폐쇄수면무호흡 진단으로 자 격이 상실됐던 운전자가 1 주일 동안 성공적으로 기도양압치 료를 받고, 최소 순응도 기준을 만족하면서 과다주간졸림이 없다면 조건부로 승인을 받을 수 있다.

캐나다흥부학회(Canadian Thoracic Society)와 캐나다수 면학회(Canadian Sleep Society)에서 2014년에 공동으로 제 안한 사업용 운전자에 대한 권고사항은 MCSAC-MRB의 권 고사항을 기반으로 하며 내용은 대동소이하다. ${ }^{34}$ 기도양압치 료 후 인증 조건에 무호흡-저호흡지수의 호전이 추가되었고, 무호흡-저호흡지수 $<10$ 회/시간을 치료 목표로 하지만 $\leq 20$ 회/시간도 허용 가능하다. 무호흡-저호흡지수의 호전은 지 속기도양압장치에서 다운로드한 데이터에서 확인할 수 있고 수면다원검사 또는 가정용수면검사를 통한 확인도 가능하 다. 기도양압치료의 순응도 평가 기간을 지난 90 일 중 연이은 30 일 이상의 기간으로 명시했다. 하지만, 비사업용 운전자의 운전적합도를 평가하기 위한 무호흡-저호흡지수의 기준은 별도로 제시하지 않았다. 이는 폐쇄수면무호흡이 운전사고 의 위험을 증가시키지만, 실제로 대부분의 환자들은 교통사 고를 겪지 않고, 게다가 무호흡-저호흡지수로 측정한 폐쇄 수면무호흡의 중증도와 교통사고 위험의 용량-반응 관계는 아직 불분명하기 때문이다. ${ }^{14}$ 또한 교통사고의 위험은 폐쇄 수면무호흡 뿐만 아니라 동반질환, 복용 약물, 과다주간졸림, 만성수면부족, 수면-각성 패턴 및 운전 습관 등 다양한 요인 에 의해서 영향을 받기 때문에, 단지 무호흡-저호흡지수만으 로 운전적합도를 평가하는 것은 적절하지 않을 수 있다. 따 라서, 비사업용 운전자에서는 종합적인 평가를 통한 교통사 고의 위험 요인들과 무호흡-저호흡지수를 함께 고려하여 운전적합도를 평가할 것을 권장했다.

비사업용 운전자에서 폐쇄수면무호흡 관련 교통사고 위험 에 대해서는 미국흥부학회(American Thoracic Society)에서 2013년에 발표한 임상진료지침이 있다. ${ }^{35}$ 본 지침에서 고위험 운전자는 중등도 이상의 과다주간졸림이 있으면서 최근 졸
음운전으로 인한 교통사고 또는 아차사고의 병력이 있는 경 우로 정의했고, 폐쇄수면무호흡이 확진된 교통사고의 고위 험 환자는 교통사고의 위험을 줄이기 위해서 지속기도양압 치료를 받아야 함을 강력히 권고했다. 또한, 폐쇄수면무호흡 이 강하게 의심되는 교통사고의 고위험 환자는 수면다원검 사와 적응증에 해당될 경우 적절한 치료를 가능한 빨리 받도 록 권고했고, 그 기간에 대해서는 근거 수준은 낮지만 1개월 이내를 목표로 할 것을 추천했다. 교통사고의 고위험 환자를 대상으로 적절한 치료가 시작되기 전까지 발생 가능한 교통 사고 위험에 대해 경고하고, 환자 및 가족을 대상으로 교통 사고를 예방하기 위한 행동요법에 대해서 교육할 것을 권장 했다. 하지만, 캐나다흥부학회와 캐나다수면학회의 권고와 마찬가지로 비사업용 운전자의 운전적합도 평가를 위한 무 호흡-저호흡지수 기준은 별도로 제시하지 않았고, 교통사고 의 병력이 없는 경우 폐쇄수면무호흡환자의 운전을 제한할 강력한 증거는 없다고 비교적 보수적인 지침을 제시했다.

영국의 운천면허청(Driver and Vehicle Licensing Agency) 의 규정은 원인에 상관없이 과다주간졸림이 있고 이로 인해 운전에 악영향이 있을 가능성이 있는 경우 운전을 하지 않 도록 권고한다. ${ }^{36}$ 무호흡-저호흡지수가 15 회/시간 이상의 중 등도 및 중증 폐쇄수면무호흡환자는 과다주간졸림이 동반된 경우 운전을 해서는 안되며 운천면허청에 신고를 해야 하고, 이는 비사업용과 사업용 운전자 모두에 해당된다. 폐쇄수면 무호흡이 효과적으로 치료되고, 과다주간졸림의 개선 및 치 료순응도가 확인되면 운전이 가능한데, 비사업용 운전자는 3 년마다 사업용 운전자는 1 년마다 인증을 받아야 한다. 무호 흡-저호흡지수가 15 회/시간 미만의 경도 폐쇄수면무호흡환 자도 일단 운전을 하면 안되지만, 운천면허청에 신고할 의무 는 없고 관련 증상이 충분히 조절되면 운전을 재개할 수 있 다. 하지만, 영국 운천면허청의 규정은 과다주간졸림에 초점 에 맞추고 있으며, 과다주간졸림이 없는 폐쇄수면무호흡에 서 운전적합도나 치료에 대한 규정은 포함되지 않았다는 제 한이 있다.

\section{폐쇄수면무호흡 환자의 운전에 대한 제안}

폐쇄수면무호흡이 운전자의 교통사고 위험을 증가시키고, 지속기도양압을 포함한 적절한 치료로 교통사고 위험을 낮 출 수 있음은 과거 연구들을 통해 충분한 컨센서스가 형성됐 다. 하지만 폐쇄수면무호흡환자에서 운전적합도를 평가하는 기준이나 운전을 제한하는 규정은 매우 복잡한 문제로 국가 별, 지역별로 다양하고 가정용수면검사 및 자동적정기도양 압 치료와 같은 진료 환경의 변화에 따라 달라진다. 그리고 사업용 운전자의 운전적합도 기준은 비사업용 운전자에 비 
해서 더 엄격해야 한다. 이는 사업용 운전자는 운전에 노출 되는 시간이 많은 만큼 전체적인 사고 위험도가 증가하고, 보다 중증의 교통사고가 발생할 위험이 높으며, 폐쇄수면무 호흡의 위험인자뿐 아니라 만성수면부족과 불규칙한 수면각성 패턴 등 과다주간졸림의 위험인자에 더욱 취약하기 때 문이다. 하지만, 현재 우리나라에는 폐쇄수면무호흡 환자의 교통사고 위험과 관련된 임상지침이나 규정이 전무하다. 그 럼에도 불구하고, 실제 임상에서 교통사고 고위험 운전자를 선별하고 동반된 수면질환을 진단 및 치료하는 것은 환자를 담당하는 수면전문가의 몫이다. 따라서, 수면전문가의 임상 진료에 도움이 될 수 있도록 본 저자들은 교통사고 위험과 관련하여 폐쇄수면무호흡 환자의 선별, 평가 및 치료에 대한 권장사항을 다음과 같이 제안한다.

\section{과다주간졸림 및 교통사고 위험 평가}

교통사고의 고위험 운전자를 선별하기 위해서 과다주간졸 림에 대한 평가를 반드시 해야 하며, 엡워스졸림척도와 같은 표준화된 평가를 사용할 것을 추천한다. 과다주간졸림 여부 는 자기보고뿐 아니라 가족이나 주변인의 보고도 도움이 된 다. 폐쇄수면무호흡 외에 과다주간졸림의 다른 가능한 원인 에 대해서 만성수면부족, 복용 약물, 음주습관, 수면-각성 패 턴, 교대근무, 동반된 다른 수면장애 및 신경계 질환, 우울증 을 포함한 정신질환의 병력을 조사한다. 또한, 교통사고 위 험과 관련하여 졸음운전 여부 및 졸음운전과 관련된 교통사 고 또는 아차사고의 병력을 반드시 조사한다. 교통사고 중 다른 설명 가능한 원인이 없는 단일차량사고(single vehicle crash)는 졸음운전의 가능성을 시사한다. 종합하여, 과다주 간졸림 또는 운전 중 졸림이 있거나 졸음운전과 관련된 교통 사고나 아차사고의 병력이 있는 경우는 교통사고의 고위험 으로 간주한다.

\section{폐쇄수면무호흡 위험도 평가}

먼저 과거 폐쇄수면무호흡의 진단 여부를 확인하고, 진단 을 받았던 환자에서는 지속기도양압 또는 기타 치료 여부, 치료 효과 및 순응도에 대한 평가가 필요하다. 폐쇄수면무호 흡의 위험도 평가 항목은 다음과 같다. 1) 증상: 과다주간졸 림, 빈번한 코골이, 수면 무호흡, 피로감, 수면 중 숨막힘, 잦 은 뒤척임, 수면 중 잦은 각성; 2) 신체검진: modified Mallampati 분류 $\geq 3$ 등급 또는 Friedman 분류 $\geq 2$ 등급, 내시경 검사를 이용한 Muller maneuver에서 상기도 폐쇄의 소견, 작은턱증 또는 아래턱후퇴증; 3) 병력: 비만(체질량지수 $\geq 30$ $\mathrm{kg} / \mathrm{m}^{2}$ ), 고혈압, 당뇨병, 심장질환, 뇌혈관질환. 이를 통해, 폐쇄수면무호흡 관련 증상이 1 개 이상 있으면서, 신체검진
또는 병력이 1 개 이상 해당되는 경우 폐쇄수면무호흡의 고 위험으로 간주한다. 교통사고 또는 폐쇄수면무호흡의 고위 험으로 평가되면 환자와 보호자에게 졸음운전과 교통사고의 위험을 설명하고 및 이를 예방하기 위한 행동요법(졸리면 운전 안 하기, 충분한 야간 수면, 낮잠, 카페인 섭취, 야간 운 전이나 장거리 운전 피하기 등)을 교육 한다.

\section{폐쇄수면무호흡의 진단 및 치료}

폐쇄수면무호흡의 고위험으로 평가되면 진단을 위한 검사 를 가능한 빨리 가급적 1 개월 이내에 시행하며, 검사실에서 감시하에 시행하는 제1형 수면다원검사를 원칙으로 한다. 폐쇄수면무호흡의 치료는 기도양압치료가 최우선 치료이며, 지속기도양압과 자동적정기도양압 둘 다 사용 가능하다. 기 도양압치료가 권장되는 적응증은 다음과 같다: 1) 무호흡저호흡지수 $\geq 15$ 회/시간의 중등도 이상의 폐쇄수면무호흡 환자, 2) 무호흡-저호흡지수 $\geq 10$ 회/시간이면서 불면증, 과다 주간졸림, 인지기능 감소, 기분장애 중 하나 이상이 있는 환 자, 3) 무호흡-저호흡지수 $\geq 5$ 회/시간이면서 고혈압, 허혈성 심장질환, 뇌졸중의 기왕력, 산소포화도 $<85 \%$, 교통사고의 고위험 중 하나 이상에 해당되는 환자. 순응도 평가는 기도 양압치료 최초 처방일로부터 90 일까지 중 연이은 30 일의 사 용기간에서 1일 4시간 이상 사용한 날이 21일(70\%) 이상을 최소 사용 기준으로 한다. 순응도 평가 자료는 양압기에 저 장된 사용 내역을 통해 확인한다. 순응에 실패한 환자는 운 전을 하지 않도록 권고하며, 최초 순응기간이 종료 후 6개월 뒤 재평가를 받을 수 있다. 폐쇄수면무호흡의 치료효과는 무 호흡-저호흡지수의 호전으로 확인한다. 치료 후 무호흡-저 호흡지수 $<5$ 회/시간을 목표로 하나 무호흡-저호흡지수가 $<15$ 회/시간이면서 치료 전에 비해 $75 \%$ 이상 감소한 경우도 허용 가능하다. 치료효과의 평가 자료는 양압기에 저장된 무 호흡-저호흡지수를 활용한다.

종합하면, 1) 무호흡-저호흡지수<5회/시간으로 폐쇄수면 무호흡이 없는 없는 자, 2) 무호흡-저호흡지수 5-15회/시간 의 경도 폐쇄수면무호흡이 있으나 치료 적응증에 포함되지 않는 자, 그리고 3) 중증도에 상관없이 폐쇄수면무호흡이 효 과적으로 치료되고 있으며, 순응도 기준을 만족하고, 과다주 간졸림이 없는 자는 운전에 적합하다(Table 3 and Supplementary Table 1 in the online-only Data Supplement). 운 전적합도를 만족하지 못한 폐쇄수면무호흡 환자에게는 잠재 적인 교통사고의 위험을 설명하고 이를 예방하기 위해 적절 한 치료가 시작되기 전까지는 운전을 중단하거나 가능한 피 하도록 권고한다. 폐쇄수면무호흡의 치료를 시작한 이후에 는 치료효과 및 순응도를 추적하고 과다주간졸림을 포함한 
Table 3. Proposed recommendations for OSA evaluation, diagnosis, and treatment

\begin{tabular}{|c|c|}
\hline Topic & Recommendations \\
\hline \multicolumn{2}{|l|}{ Driving risk } \\
\hline Sleepiness symptoms & EDS or sleepiness at the wheel \\
\hline Accident history & History of sleepiness-related motor vehicle crashes or near-miss accidents \\
\hline \multicolumn{2}{|l|}{ OSA risk } \\
\hline Symptoms & $\begin{array}{l}\text { EDS, habitual snoring, witnessed apnea, nonrestorative sleep, gasping/choking at night, frequent tossing } \\
\text { and turning, or frequent awakening during sleep }\end{array}$ \\
\hline Physical exam & $\begin{array}{l}\text { Modified Mallampati score } \geq \text { grade } 3 \text {, Friedman staging } \geq \text { grade } 2 \text {, } \\
\text { upper airway obstruction confirmed by the Muller maneuver, micrognathia, or retrognathia }\end{array}$ \\
\hline Medical history & $\begin{array}{l}\text { Obesity (body mass index }>30 \mathrm{~kg} / \mathrm{m}^{2} \text { ), history of hypertension, type } 2 \text { diabetes, heart disease, } \\
\text { or cerebrovascular diseases }\end{array}$ \\
\hline \multicolumn{2}{|l|}{ OSA diagnosis and treatment } \\
\hline PSG & In-lab (level 1) PSG is recommended for those at high risk of OSA* \\
\hline OSA treatment & $\begin{array}{l}\text { PAP is the treatment of choice for OSA } \\
\text { PAP pressure can be established by either a titration study or an autotitration system } \\
\text { Treatment is recommended if } 1 \text { ) AHI } \geq 15 \text { events/hr, 2) AHI } \geq 10 \text { events/hr and at least one of insomnia, } \\
\text { EDS, cognitive decline, and mood disorders, or } 3 \text { ) AHI } \geq 5 \text { events/hr and at least one of hypertension, } \\
\text { ischemic heart disease, stroke, oxygen saturation }<85 \% \text {, and high-risk drivers }{ }^{\dagger}\end{array}$ \\
\hline PAP adherence & $\begin{array}{l}\text { At least } 4 \text { hours per day of use on } 70 \% \text { of days over at least a } 30 \text {-day period of time performed within the } \\
\text { previous } 90 \text { days }\end{array}$ \\
\hline Effectiveness of treatment & $\begin{array}{l}\text { Post-treatment AHI }<5 \text { events/hr (optimal) } \\
\text { Post-treatment AHI }<15 \text { events/hr and } \geq 75 \% \text { reduction from baseline (acceptable) }\end{array}$ \\
\hline Fit to drive & $\begin{array}{l}\text { 1) AHI }<5 \text { events/hr, or } \\
\text { 2) AHI } 5-15 \text { events/hr but treatment is not recommended, or } \\
\text { 3) OSA is being effectively treated, the adherence criteria are met, and there is no EDS }\end{array}$ \\
\hline
\end{tabular}

*a high risk of OSA is defined as those who have at least one symptom related to OSA and have at least one physical examination or medical history; thigh-risk drivers are defined as those who report EDS or sleepiness at the wheel, or have a history of sleepiness-related motor vehicle crashes or near-miss accidents in the past five years. OSA, obstructive sleep apnea; EDS, excessive daytime sleepiness; PSG, polysomnography; AHI, apnea-hypopnea index; PAP, positive airway pressure; HSAT, home sleep apnea testing

교통사고 위험이 감소되었는지 재평가한다. 특히, 순응도 평 가기준을 만족한 경우에도 치료효과를 최대화하기 위해 기 도양압을 가능한 많이 사용하도록 격려한다. 하지만, 폐쇄수 면무호흡에 대한 치료를 시작한 후에도, 1) 과다주간졸림 또 는 운전 중 졸림을 경험하거나, 2) 졸음운전과 관련된 교통 사고 또는 아차사고가 발생하거나, 3) 치료효과 또는 순응도 평가에 실패한 운전자는 일단 운전을 피하도록 권고하고 해 결되지 않은 문제에 대한 추가적인 조치를 취한다.

\section{결 론}

본 종설을 통해 제시하는 폐쇄수면무호흡 환자에서 졸음 운전 관련 교통사고 예방을 위한 제안은 폐쇄수면무호흡 환 자와 의사 모두 교통사고의 위험요인으로서 폐쇄수면무호흡 의 중요성을 인식하고 졸음운전과 관련된 교통사고의 위험 을 줄이기 위한 교육과 치료의 필요성을 이해하는데 도움을 제공하기 위함이다. 최근 폐쇄수면무호흡 환자에서 수면다
원검사와 기도양압치료의 보험급여가 인정되면서 접근성 및 이용가능성이 개선되었다. 이에 본 제안에서는 우리나라 의 료현실을 반영하기 위해 2018년 수면무호흡증에 대한 수면 다원검사의 요양급여 인정 기준과 2020년 개정된 양압기 보 험급여 기준을 포함하도록 폐쇄수면무호흡의 진단과 치료 기준을 설정했다. 비록 우리나라에서 아직까지 폐쇄수면무 호흡 환자의 운전에 대한 법 규정은 없으나, 공중보건문제로 서 졸음운전의 위험과 대중의 운전을 과도하게 제한하는 우 려 사이의 적절한 균형을 유지할 수 있는 규정이 마련되어야 할 것이다. 본 제안은 향후 법적 기준의 큰 틀을 제공할 수는 있겠으나, 세부항목들에 대한 최적의 기준을 결정하기 위해 서는 앞으로 많은 연구가 필요하다. 예를 들어, 폐쇄수면무 호흡 환자에서 교통사고의 고위험군을 보다 효과적으로 선 별하기 위한 방법, 특히 각성유지검사나 모의운전장치 등의 객관적인 검사의 유용성을 규명하기 위한 노력이 필요하다. 또한 본 종설에서는 운전자에 대한 별도 구분 없이 운전적합 도에 대한 일반적인 기준을 제안했으나, 이는 비사업용 운전 
자에 대한 기준이 너무 엄격하게 정해졌을 가능성을 배제할 수 없다. 기도양압치료에 성공한 운전자에서 운전적합도의 재평가가 필요할지, 필요하다면 그 간격을 결정하기 위한 의 학적 근거를 필요하다. 마지막으로, 기도양압 외 치료(비만 수술, 상기도수술, 구강 내 장치 등) 후 운전적합도 판정기준 이나 운전적합도를 평가하는 수면전문의의 자격 기준도 앞 으로 마련되어야 할 것이다. 이와 같이 해결되지 않은 많은 문제들이 있음에도 불구하고 처음으로 폐쇄수면무호흡환자 의 운전적합도에 대한 합리적인 기준을 제시했다는 것이 중 요하겠으며, 본 제안이 앞으로 더 많은 연구와 사회적 논의 를 촉진하기를 바란다.

\section{Supplementary Materials}

The online-only Data Supplement is available with this article at https:// doi.org/10.13078/jsm.210024.

\section{Conflicts of Interest}

The authors have no potential conflicts of interest to disclose.

\section{ORCID iDs}

Jun-Sang Sunwoo

Jae Wook Cho

Soo Hwan Yim

Daeyoung Kim

Dae Lim Koo

Hee-Jin Im

Hyeyun Kim

Kyung Min Kim

Kwang Ik Yang

https://orcid.org/0000-0001-8834-0568 https://orcid.org/0000-0002-2742-9136 https://orcid.org/0000-0003-2948-9244 https://orcid.org/0000-0001-9056-0017 https://orcid.org/0000-0001-6858-6093 https://orcid.org/0000-0002-8979-6521 https://orcid.org/0000-0002-8008-5539 https://orcid.org/0000-0002-0261-1687 https://orcid.org/0000-0001-6343-6520

\section{Author Contributions}

Conceptualization: Jun-Sang Sunwoo, Kwang IK Yang. Funding acquisition: Kwang IK Yang. Investigation: Jun-Sang Sunwoo, Jae Wook Cho, Soo Hwan Yim, Daeyoung Kim. Methodology: Dae Lim Koo, Hee-Jin Im, Hyeyun Kim, Kyung Min Kim. Project administration: Kwang IK Yang. Writing_original draft: Jun-Sang Sunwoo, Kwang IK Yang. Writing_review \& editing: Jae Wook Cho, Soo Hwan Yim, Daeyoung Kim, Dae Lim Koo, Hee-Jin Im, Hyeyun Kim, Kyung Min Kim.

\section{Funding Statement}

None.

\section{REFERENCES}

1. Lévy P, Kohler M, McNicholas WT, et al. Obstructive sleep apnoea syndrome. Nat Rev Dis Primers 2015;1:15015. https://doi.org/10.1038/ nrdp.2015.15.

2. Kim J, In K, Kim J, et al. Prevalence of sleep-disordered breathing in middle-aged Korean men and women. Am J Respir Crit Care Med 2004;170:1108-1113. https://doi.org/10.1164/rccm.200404-519OC.

3. Knauert M, Naik S, Gillespie MB, Kryger M. Clinical consequences and economic costs of untreated obstructive sleep apnea syndrome. World J Otorhinolaryngol Head Neck Surg 2015;1:17-27. https://doi. org/10.1016/j.wjorl.2015.08.001.

4. Garbarino S, Guglielmi O, Sanna A, Mancardi GL, Magnavita N. Risk of occupational accidents in workers with obstructive sleep apnea: systematic review and meta-analysis. Sleep 2016;39:1211-1218. https:// doi.org/10.5665/sleep.5834.
5. Bioulac S, Micoulaud-Franchi JA, Arnaud M, et al. Risk of motor vehicle accidents related to sleepiness at the wheel: a systematic review and meta-analysis. Sleep 2017;40:zsx134. https://doi.org/10.1093/sleep/ zsx134.

6. Tefft BC. Prevalence of motor vehicle crashes involving drowsy drivers, United States, 2009-2013 [Internet]. Washington, DC: AAA Foundation for Traffic Safety, 2014 [cited 2021 Nov 12]. Available from: https://aaafoundation.org/wp-content/uploads/2017/12/PrevalenceofMVCDrowsyDriversReport.pdf.

7. Sassani A, Findley LJ, Kryger M, Goldlust E, George C, Davidson TM. Reducing motor-vehicle collisions, costs, and fatalities by treating obstructive sleep apnea syndrome. Sleep 2004;27:453-458. https://doi. org/10.1093/sleep/27.3.453.

8. Kim KT, Jung KY. Current status and proposal of drowsy driving. $J$ Sleep Med 2016;13:35-39. https://doi.org/10.13078/jsm.16007.

9. Tregear S, Reston J, Schoelles K, Phillips B. Obstructive sleep apnea and risk of motor vehicle crash: systematic review and meta-analysis. $J$ Clin Sleep Med 2009;5:573-581. https://doi.org/10.5664/jcsm.27662.

10. Antonopoulos CN, Sergentanis TN, Daskalopoulou SS, Petridou ET. Nasal continuous positive airway pressure (nCPAP) treatment for obstructive sleep apnea, road traffic accidents and driving simulator performance: a meta-analysis. Sleep Med Rev 2011;15:301-310. https://doi. org/10.1016/j.smrv.2010.10.002.

11. Yim SH, Cho JW, Sunwoo JS, et al. Sleep disorders and risk of motor vehicle accident. J Sleep Med 2021;18:72-77. https://doi.org/10.13078/ jsm.210017.

12. Young T, Blustein J, Finn L, Palta M. Sleep-disordered breathing and motor vehicle accidents in a population-based sample of employed adults. Sleep 1997;20:608-613. https://doi.org/10.1093/sleep/20.8.608.

13. Terán-Santos J, Jiménez-Gómez A, Cordero-Guevara J. The association between sleep apnea and the risk of traffic accidents. Cooperative Group Burgos-Santander. N Engl J Med 1999;340:847-851. https://doi. org/10.1056/NEJM199903183401104.

14. Mulgrew AT, Nasvadi G, Butt A, et al. Risk and severity of motor vehicle crashes in patients with obstructive sleep apnoea/hypopnoea. Tho$\operatorname{rax}$ 2008;63:536-541. https://doi.org/10.1136/thx.2007.085464.

15. Sunwoo JS, Hwangbo Y, Kim WJ, Chu MK, Yun CH, Yang KI. Sleep characteristics associated with drowsy driving. Sleep Med 2017;40:410. https://doi.org/10.1016/j.sleep.2017.08.020.

16. Wong CK, Fung CS, Siu SC, et al. The impact of work nature, lifestyle, and obesity on health-related quality of life in Chinese professional drivers. J Occup Environ Med 2012;54:989-994. https://doi.org/10.1097/ JOM.0b013e3182535d7d.

17. Sunwoo JS, Shin DS, Hwangbo Y, et al. High risk of obstructive sleep apnea, insomnia, and daytime sleepiness among commercial motor vehicle drivers. Sleep Breath 2019;23:979-985. https://doi.org/10.1007/ s11325-019-01805-7.

18. Howard ME, Desai AV, Grunstein RR, et al. Sleepiness, sleep-disordered breathing, and accident risk factors in commercial vehicle drivers. Am J Respir Crit Care Med 2004;170:1014-1021. https://doi.org/10.1164/ rccm.200312-1782OC.

19. Young T, Palta M, Dempsey J, Skatrud J, Weber S, Badr S. The occurrence of sleep-disordered breathing among middle-aged adults. N Engl J Med 1993;328:1230-1235. https://doi.org/10.1056/NEJM199304293281704.

20. Meuleners L, Fraser ML, Govorko MH, Stevenson MR. Obstructive sleep apnea, health-related factors, and long distance heavy vehicle crashes in Western Australia: a case control study. J Clin Sleep Med 2015; 11:413-418. https://doi.org/10.5664/jcsm.4594.

21. Young T, Peppard PE, Gottlieb DJ. Epidemiology of obstructive sleep apnea: a population health perspective. Am J Respir Crit Care Med 2002;165:1217-1239. https://doi.org/10.1164/rccm.2109080.

22. Garbarino S, Durando P, Guglielmi O, et al. Sleep apnea, sleep debt and daytime sleepiness are independently associated with road accidents. A cross-sectional study on truck drivers. PLoS One 2016;11:e0166262. https://doi.org/10.1371/journal.pone.0166262. 
23. Kim D, Shin DS, Lee SC, et al. Sleep status and the risk factor of drowsyrelated accidents in commercial motor vehicle drivers. Sleep Med Res 2018;9:97-103. https://doi.org/10.17241/smr.2018.00283.

24. Stoohs RA, Guilleminault C, Itoi A, Dement WC. Traffic accidents in commercial long-haul truck drivers: the influence of sleep-disordered breathing and obesity. Sleep 1994;17:619-623. https://doi.org/10.1093/ sleep/17.7.619.

25. Karimi M, Hedner J, Häbel H, Nerman O, Grote L. Sleep apnea-related risk of motor vehicle accidents is reduced by continuous positive airway pressure: Swedish traffic accident registry data. Sleep 2015;38:341349. https://doi.org/10.5665/sleep.4486.

26. Kushida CA, Littner MR, Hirshkowitz M, et al. Practice parameters for the use of continuous and bilevel positive airway pressure devices to treat adult patients with sleep-related breathing disorders. Sleep 2006; 29:375-380. https://doi.org/10.1093/sleep/29.3.375.

27. Sunwoo JS, Yang KI. Overview of treatment for obstructive sleep apnea in adults. J Sleep Med 2017;14:1-9. https://doi.org/10.13078/jsm.17001.

28. George CF. Reduction in motor vehicle collisions following treatment of sleep apnoea with nasal CPAP. Thorax 2001;56:508-512. http://dx. doi.org/10.1136/thx.56.7.508.

29. Hack M, Davies RJ, Mullins R, et al. Randomised prospective parallel trial of therapeutic versus subtherapeutic nasal continuous positive airway pressure on simulated steering performance in patients with obstructive sleep apnoea. Thorax 2000;55:224-231. https://doi.org/10.1136/ thorax.55.3.224.

30. McMillan A, Bratton DJ, Faria R, et al. Continuous positive airway pressure in older people with obstructive sleep apnoea syndrome (PRE-
DICT): a 12-month, multicentre, randomised trial. Lancet Respir Med 2014;2:804-812. https://doi.org/10.1016/S2213-2600(14)70172-9.

31. Colvin LJ, Dace GA, Colvin RM, Ojile J, Collop N. Commercial motor vehicle driver positive airway pressure therapy adherence in a sleep center. J Clin Sleep Med 2016;12:477-485. https://doi.org/10.5664/ jcsm. 5670 .

32. Weaver TE, Maislin G, Dinges DF, et al. Relationship between hours of CPAP use and achieving normal levels of sleepiness and daily functioning. Sleep 2007;30:711-719. https://doi.org/10.1093/sleep/30.6.711.

33. Parker DR, Hoffman BH. MCSAC and MRB task 11-05-final report on obstructive sleep apnea (OSA) [Internet]. Washington, DC: Federal Motor Carrier Safety Administration, 2012 Feb 6 [cited 2021 Nov 7]. Available from: https://www.fmcsa.dot.gov/february-6-2012-mcsacand-mrb-task-11-05-final-report-obstructive-sleep-apnea-osa.

34. Ayas N, Skomro R, Blackman A, et al. Obstructive sleep apnea and driving: a Canadian Thoracic Society and Canadian Sleep Society position paper. Can Respir J 2014;21:114-123. https://doi.org/10.1155/2014/357327.

35. Strohl KP, Brown DB, Collop N, et al. An official American Thoracic Society clinical practice guideline: sleep apnea, sleepiness, and driving risk in noncommercial drivers. An update of a 1994 statement. Am J Respir Crit Care Med 2013;187:1259-1266. https://doi.org/10.1164/ rccm.201304-0726ST.

36. Driver and Vehicle Licensing Agency. Assessing fitness to drive: a guide for medical professionals [Internet]. Swansea: GOV.UK, 2016 Mar 11 [cited 2021 Nov 9]. Available from: https://www.gov.uk/government/publications/assessing-fitness-to-drive-a-guide-for-medicalprofessionals. 
Supplementary Table 1. 졸음운전 관련 교통사고 예방을 위한 폐쇄수면무호흡의 평가, 진단 및 치료에 대한 제안

교통사고 위험 평가

졸림 증상 과다주간졸림 또는 운전 중 졸림

교통사고 병력 졸음운전과 관련된 교통사고 또는 아차사고의 병력

폐쇄수면무호흡 위험도 평가

증상

과다주간졸림, 빈번한 코골이, 수면 무호흡, 피로감, 수면 중 숨막힘, 잦은 뒤척임, 수면 중 잦은 각성

신체검진

Modified Mallampati 분류 $\geq 3$ 등급 또는 Friedman 분류 $\geq 2$ 등급, 내시경검사를 이용한 Muller maneuver에서 상기도 폐쇄의 소견, 작은턱증 또는 아래턱후퇴증

병력 비만(체질량지수 $\geq 30 \mathrm{~kg} / \mathrm{m}^{2}$ ), 고혈압, 당뇨병, 심장질환, 뇌혈관질환

폐쇄수면무호흡의 진단 및 치료

수면다원검사

폐쇄수면무호흡의 고위험*으로 평가되면 진단을 위해 제 1 형(Level 1) 수면다원검사가 권장된다.

치료 원칙

기도양압치료가 폐쇄수면무호흡의 최우선 치료이며, 지속기도양압과 자동적정기도양압 둘 다 사용 가능하다.

다음 중 하나에 해당하면 기도양압치료가 권장된다: 1) 무호흡-저호흡지수 $\geq 15$ 회/시간의 중등도 이상의 폐쇄수면무호흡 환자, 2) 무호흡-저호흡지수 $\geq 10$ 회/시간이면서 불면증, 과다주간졸림, 인 지기능 감소, 기분장애 중 하나 이상이 있는 환자, 3) 무호흡-저호흡지수 $\geq 5$ 회/시간이면서 고혈압, 허혈성 심장질환, 뇌졸중의 기왕력, 산소포화도 < $85 \%$, 교통사고의 고위험† 중 하나 이상에 해당되 는 환자.

순응도 기도양압치료 최초 처방일로부터 90 일까지 중 연이은 30 일의 사용기간에서 1 일 4 시간 이상 사용한 날이 21일(70\%) 이상을 최소 순응도 기준으로 한다.

치료효과 치료 후 무호흡-저호흡지수 $<5$ 회/시간을 목표로 하지만, 무호흡-저호흡지수가 <15회/시간이면서 치료 전에 비해 $75 \%$ 이상 감소한 경우도 허용 가능하다.

운전적합도 기준 다음 중 하나에 해당하면 운전에 적합하다: 1) 무호흡-저호흡지수 <5회/시간으로 폐쇄수면무호흡 이 없는 없는 자, 2) 무호흡-저호흡지수 5-15회/시간의 경도 폐쇄수면무호흡이 있으나 치료 적응 증에 포함되지 않는 자, 3) 중증도에 상관없이 폐쇄수면무호흡이 효과적으로 치료되고 있으며, 순 응도 기준을 만족하고, 과다주간졸림이 없는 자

*폐쇄수면무호흡의 고위험은 폐쇄수면무호흡 관련 증상이 1개 이상 있으면서, 신체검진 또는 병력이 1 개 이상 해당되는 경우 로 정의한다; †교통사고의 고위험은 과다주간졸림 또는 운전 중 졸림이 있거나 졸음운전과 관련된 교통사고나 아차사고의 병력 이 있는 경우로 정의한다 